\title{
Once-daily long-acting beta-agonists for chronic obstructive pulmonary disease: an indirect comparison of olodaterol and indacaterol
}

This article was published in the following Dove Press journal:

International Journal of COPD

31 July 2014

Number of times this article has been viewed

\section{Neil S Roskell' \\ Antonio Anzueto 2 \\ Alan Hamilton ${ }^{3}$ \\ Bernd Disse ${ }^{4}$ \\ Karin Becker ${ }^{5}$}

'Statistics, Bresmed Health

Solutions Ltd, Sheffield, UK;

${ }^{2}$ School of Medicine, University

of Texas Health Science Center,

San Antonio, TX, USA; ${ }^{3}$ Medical

Department, Boehringer Ingelheim

(Canada) Ltd, Burlington, ON,

Canada; ${ }^{4}$ Medical Department,

Boehringer Ingelheim $\mathrm{GmbH}$,

Ingelheim am Rhein, Germany;

${ }^{5}$ Global Health Economics and

Outcomes Research, Boehringer

Ingelheim $\mathrm{GmbH}$, Ingelheim am

Rhein, Germany
Correspondence: Neil S Roskell

BresMed Health Solutions Ltd,

North Church House, 84 Queen Street

Sheffield SI 2DW, UK

Tel +44 II43094372

Email nroskell@bresmed.co.uk
Purpose: In the absence of head-to-head clinical trials comparing the once-daily, long-acting beta2-agonists olodaterol and indacaterol for the treatment of chronic obstructive pulmonary disease (COPD), an indirect treatment comparison by systematic review and synthesis of the available clinical evidence was conducted.

Methods: A systematic literature review of randomized, controlled clinical trials in patients with COPD was performed to evaluate the efficacy and safety of olodaterol and indacaterol. Network meta-analysis and adjusted indirect comparison methods were employed to evaluate treatment efficacy, using outcomes based on trough forced expiratory volume in 1 second $\left(\mathrm{FEV}_{1}\right)$, Transition Dyspnea Index, St George's Respiratory Questionnaire total score and response, rescue medication use, and proportion of patients with exacerbations.

Results: Eighteen trials were identified for meta-analysis (eight, olodaterol; ten, indacaterol). Olodaterol trials included patients of all severities, whilst indacaterol trials excluded patients with very severe COPD. Concomitant maintenance bronchodilator use was allowed in most olodaterol trials, but not in indacaterol trials. When similarly designed trials/data were analyzed for change from baseline in trough $\mathrm{FEV}_{1}$ (liters), the following mean differences $(95 \%$ confidence interval) were observed: trials excluding concomitant bronchodilator: indacaterol $75 \mathrm{mcg}$ versus olodaterol $5 \mathrm{mcg},-0.005$ ( -0.077 to 0.067 ), and indacaterol $150 \mathrm{mcg}$ versus olodaterol $5 \mathrm{mcg}, 0.020$ (-0.036 to 0.077 ); trials with concomitant tiotropium: indacaterol $150 \mathrm{mcg}$ versus olodaterol $5 \mathrm{mcg}, 0.000$ ( -0.043 to 0.042 ). In sensitivity analyses of the full network, results for change from baseline in trough $\mathrm{FEV}_{1}$ favored indacaterol, but this dataset suffered from trial design heterogeneity. For the other endpoints investigated, no statistically significant differences were found when analyzed in the full network.

Conclusion: When compared under similar trial conditions, olodaterol and indacaterol have similar efficacy in patients with COPD. This research highlights the importance of considering the concomitant COPD medication when evaluating treatment effects in COPD.

Keywords: COPD, olodaterol, indacaterol, meta-analysis, systematic review, LABA

\section{Introduction}

Chronic obstructive pulmonary disease (COPD) is a chronic respiratory disease characterized by a progressive decline in lung function and accompanied by respiratory symptoms, primarily dyspnea, cough, and sputum production. ${ }^{1,2}$ Given the progressive nature of the disease, the aim of treatments is to reduce symptoms and exacerbations, thereby improving health-related quality of life. Currently, the Global Initiative for Chronic Obstructive Lung Disease (GOLD) guidelines recommend initiation with a short-acting bronchodilator, followed by the addition of long-acting bronchodilators as symptoms and/or risk of exacerbations increase, and eventually adding inhaled steroids 
and/or roflumilast. ${ }^{2}$ Commonly used bronchodilators include inhaled long-acting beta2-agonists (LABAs) (eg, twicedaily formoterol, twice-daily salmeterol, and more recently once-daily indacaterol), inhaled long-acting antimuscarinic agents (LAMAs) (eg, once-daily tiotropium, and recently twice-daily aclidinium and once-daily glycopyrronium), and oral methylxanthines (eg, theophylline). Bronchodilators improve lung function, reduce symptoms and exacerbations, and improve health-related quality of life. ${ }^{2}$ Bronchodilators are frequently used in combination when higher effect sizes are warranted.

In trials where a LABA was administered in addition to a LAMA, the observed effect sizes were greater than those with either LABA or LAMA alone, ${ }^{3,4}$ and in some cases the effects of the monotherapies have been shown to be additive when used in combination. ${ }^{5}$ However, effect sizes of bronchodilator monotherapies are not always additive, as seen in published trials of bronchodilator combinations. Most recently, this was demonstrated with indacaterol, where the effect size of indacaterol administered with tiotropium compared with tiotropium monotherapy was much lower than the effect sizes observed in studies that compared indacaterol monotherapy with placebo. ${ }^{6}$ Furthermore, more recent trials have found that monotherapy treatments have shown lower increases in forced expiratory volume in 1 second $\left(\mathrm{FEV}_{1}\right)$, compared to trials of the same investigational drug performed 5 or 10 years earlier. This may be due to evolution in trial designs, where, for example, later trials are more likely to permit concomitant treatment with other bronchodilators as part of usual care. ${ }^{7}$ Additionally, there is evidence that the effect of bronchodilators varies depending on the severity of the patient's COPD. Patients with very severe COPD show lower improvement of $\mathrm{FEV}_{1}$ when treated with bronchodilators, compared with patients with moderate or severe COPD. ${ }^{8,9}$

The LABA olodaterol has been developed as a once-daily long-acting bronchodilator for maintenance treatment of COPD. Phase III clinical trials of olodaterol have been completed, and the product, at the $5 \mathrm{mcg}$ per day dose, has been approved in a number of European countries and Canada, and is currently under regulatory review in the United States by the Food and Drug Administration (FDA) ${ }^{10}$ and other regulatory agencies.

To date, indacaterol is the only other once-daily LABA approved and made available in many countries worldwide. Indacaterol has been licensed in the United States and Canada at a dose of $75 \mathrm{mcg}$ per day. ${ }^{11,12}$ In most other countries, two doses are licensed: $150 \mathrm{mcg}$ per day and
$300 \mathrm{mcg}$ per day for those patients for whom $150 \mathrm{mcg}$ is not sufficient. ${ }^{13}$

In the absence of head-to-head, randomized controlled clinical trials (RCTs) conducted on LABAs, the primary objective of this systematic literature review and meta-analysis was to provide estimates of relative efficacy of two new once-daily LABAs, olodaterol and indacaterol. A network meta-analysis was performed to indirectly compare the two treatments, linked through common treatment comparators. The review made two specific treatment comparisons: olodaterol $5 \mathrm{mcg}$ compared with indacaterol $150 \mathrm{mcg}$, and olodaterol $5 \mathrm{mcg}$ compared with indacaterol $75 \mathrm{mcg}$.

\section{Methods}

A comprehensive and systematic literature review to identify RCTs studying olodaterol and indacaterol in COPD was undertaken to establish the evidence base for use in the meta-analyses.

\section{Systematic review process}

A systematic literature review was performed according to a prespecified protocol, to comply with the requirements of the National Institute for Health and Care Excellence single technology assessment. ${ }^{14}$ The following electronic databases were searched: 1) The Cochrane Library, including the Cochrane Database of Systematic Reviews, the Cochrane Central Register of Controlled Trials, and the Database of Abstracts of Reviews of Effectiveness; 2) MEDLINE and MEDLINE In-Process; and 3) Embase. In addition, the following additional sources were searched to identify conference abstracts and published and unpublished studies: web sites for conference abstracts from the following organizations: American Thoracic Society (2010 and 2011), European Respiratory Society (2009 and 2010), and British Thoracic Society (Winter 2009 and Winter 2010); bibliographic reference lists of the included studies and reviews (searched for other relevant published studies); TrialTrove (http://www.citeline.com/products/ trialtrove/overview/); ClinicalTrials.gov (http://www.clinicaltrials.gov/); web sites for the FDA and European Medicines Agency; and the Boehringer Ingelheim Trial Database for olodaterol studies.

Database search terms included combinations of free text and medical subject headings. The full search strategy for MEDLINE is presented in the Supplementary material. The search strategy for each database is available from the authors upon request.

The search strategies relied on three sets of terms: health condition of interest (COPD), study type (RCTs), and 
intervention (olodaterol and/or indacaterol). Appropriate terms were combined, and iterative searches were performed using other relevant terms and concepts.

The searches were limited to articles published from 1 January 1990, through 5 August 2011, given the development timelines of the two compounds under study. Articles in languages other than English were excluded.

During systematic review and meta-analysis planning and execution, data for olodaterol were not publicly available, therefore, data on file with Boehringer Ingelheim were used. Most data are now publicly available in the primary publications and/or on the FDA web site, in the briefing documents for a Pulmonary and Allergy Drug Advisory Committee meeting held in January 2013. ${ }^{10,15-18}$ All data, including data not published in the Pulmonary and Allergy Drug Advisory Committee document, are listed in the Supplementary material.

Two experienced literature reviewers screened and selected identified studies independently before comparing results. Any disagreements were discussed with the research team to reach a consensus about study inclusion. During screening, further exclusions of studies were based on lack of outcome data, lack of a link into the treatment network, and study length (ie, studies lasting less than 6 weeks). Data extraction was performed by an experienced literature reviewer and quality checked by the statistician responsible for the meta-analyses.

Quality assessments were conducted for each included trial, using quality criteria recommended by the Centre for Reviews and Dissemination. ${ }^{19}$ Full details of this assessment can be found in the Supplementary material.

\section{Outcomes}

Four continuous and two dichotomous outcomes were considered for meta-analysis. Trough $\mathrm{FEV}_{1}$ was analyzed as change from baseline in liters at week 12. Similar trough $\mathrm{FEV}_{1}$ data at week 6 were permitted in the absence of week 12 data. Other lung-function outcomes were considered for analysis, but trough $\mathrm{FEV}_{1}$ was selected because it was the only outcome consistently reported across the evidence base. While the area under the $\mathrm{FEV}_{1}$-time curve (0-3 hours post-dose) was reported in all olodaterol trials, it was not reported for the indacaterol 150 or $75 \mathrm{mcg}$ studies and so could not be included in the meta-analysis. St George's Respiratory Questionnaire (SGRQ) total score was analyzed as change from baseline at week 12. The proportion of responders based on SGRQ total score was analyzed at week 12, response was defined as a decrease (improvement) in SGRQ total score of at least 4 points. Transition Dyspnea Index (TDI), by definition a change from baseline

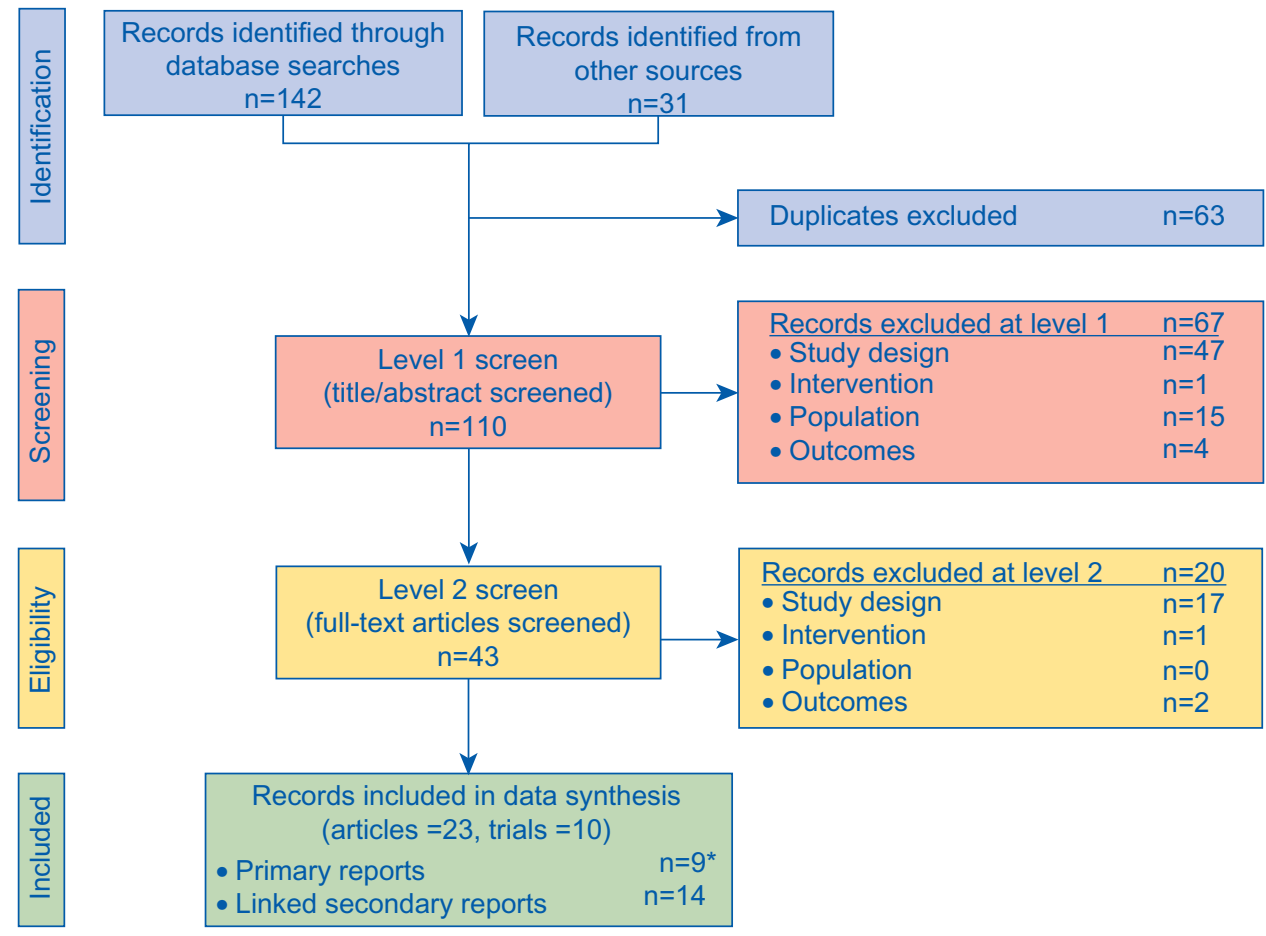

Figure I PRISMA flow diagram of the literature review.

Note: *One primary report described two separate trials.

Abbreviation: PRISMA, Preferred Reporting Items for Systematic Reviews and Meta-Analyses. 
Table I Included trials/treatments and important comedications and inclusion criteria

\begin{tabular}{|c|c|c|c|c|c|c|}
\hline $\begin{array}{l}\text { Study name } \\
\text { or code }\end{array}$ & Interventions & $\begin{array}{l}\text { Number } \\
\text { randomized }\end{array}$ & $\begin{array}{l}\text { Received } \\
\text { concomitant } \\
\text { LAMA }\end{array}$ & $\begin{array}{l}\text { Received } \\
\text { concomitant } \\
\text { xanthines }\end{array}$ & $\begin{array}{l}\text { Received } \\
\text { concomitant } \\
\text { SAMA }\end{array}$ & $\begin{array}{l}\text { GOLD } \\
\text { stage IV } \\
\text { at baseline }\end{array}$ \\
\hline \multirow[t]{3}{*}{1222.11} & Olodaterol 5 mcg & 208 & $21 \%$ & $14 \%$ & $22 \%$ & $14 \%$ \\
\hline & Olodaterol $10 \mathrm{mcg}$ & 207 & $25 \%$ & $15 \%$ & $20 \%$ & $10 \%$ \\
\hline & Placebo & 209 & $25 \%$ & $14 \%$ & $20 \%$ & $12 \%$ \\
\hline \multirow[t]{3}{*}{1222.12} & Olodaterol 5 mcg & 209 & $16 \%$ & $12 \%$ & $14 \%$ & $11 \%$ \\
\hline & Olodaterol $10 \mathrm{mcg}$ & 217 & $22 \%$ & $10 \%$ & $18 \%$ & $12 \%$ \\
\hline & Placebo & 216 & $18 \%$ & $12 \%$ & $19 \%$ & $17 \%$ \\
\hline \multirow[t]{4}{*}{1222.13} & Olodaterol 5 mcg & 227 & $26 \%$ & $15 \%$ & $34 \%$ & $6 \%$ \\
\hline & Olodaterol $10 \mathrm{mcg}$ & 225 & $26 \%$ & $15 \%$ & $26 \%$ & $9 \%$ \\
\hline & Formoterol $12 \mathrm{mcg}$ & 227 & $26 \%$ & $16 \%$ & $30 \%$ & $7 \%$ \\
\hline & Placebo & 225 & $25 \%$ & $16 \%$ & $33 \%$ & $9 \%$ \\
\hline \multirow[t]{4}{*}{1222.14} & Olodaterol 5 mcg & 232 & $25 \%$ & $23 \%$ & $29 \%$ & $7 \%$ \\
\hline & Olodaterol $10 \mathrm{mcg}$ & 234 & $27 \%$ & $19 \%$ & $27 \%$ & $6 \%$ \\
\hline & Formoterol $12 \mathrm{mcg}$ & 233 & $25 \%$ & $19 \%$ & $28 \%$ & $9 \%$ \\
\hline & Placebo & 235 & $26 \%$ & $18 \%$ & $26 \%$ & $11 \%$ \\
\hline \multirow[t]{4}{*}{$1222.24^{\mathrm{a}}$} & Olodaterol 5 mcg & 99 & $15 \%^{\mathrm{b}}$ & $0 \%$ & $18 \%^{\mathrm{b}}$ & $9 \%$ \\
\hline & Olodaterol $10 \mathrm{mcg}$ & & & & & \\
\hline & Formoterol $12 \mathrm{mcg}$ & & & & & \\
\hline & Placebo & & & & & \\
\hline \multirow[t]{4}{*}{$1222.25^{a}$} & Olodaterol 5 mcg & 100 & $31 \%$ & $1 \%{ }^{\mathrm{b}}$ & $12 \%^{\mathrm{b}}$ & $5 \%$ \\
\hline & Olodaterol $10 \mathrm{mcg}$ & & & & & \\
\hline & Formoterol $12 \mathrm{mcg}$ & & & & & \\
\hline & Placebo & & & & & \\
\hline \multirow[t]{4}{*}{$1222.39^{a}$} & Olodaterol 5 mcg & 108 & $0 \%$ & $8 \%$ & $13 \%$ & $5 \%$ \\
\hline & Olodaterol $10 \mathrm{mcg}$ & & & & & \\
\hline & Tiotropium 18 mcg & & & & & \\
\hline & Placebo & & & & & \\
\hline \multirow[t]{4}{*}{$1222.40^{\mathrm{a}}$} & Olodaterol 5 mcg & 122 & $0 \%$ & $6 \%$ & $14 \%$ & $9 \%$ \\
\hline & Olodaterol $10 \mathrm{mcg}$ & & & & & \\
\hline & Tiotropium $18 \mathrm{mcg}$ & & & & & \\
\hline & Placebo & & & & & \\
\hline \multirow[t]{3}{*}{$\mathrm{B} \mid 302$} & Indacaterol $150 \mathrm{mcg}$ & 114 & $0 \%$ & NR & NR & $0 \%$ \\
\hline & Indacaterol $300 \mathrm{mcg}$ & 116 & & & & \\
\hline & Placebo & 117 & & & & \\
\hline \multirow[t]{3}{*}{ B220I } & Indacaterol $400 \mathrm{mcg}$ & 68 & $0 \%$ & NR & NR & $0 \%$ \\
\hline & Indacaterol $800 \mathrm{mcg}$ & 67 & & & & \\
\hline & Placebo & 28 & & & & \\
\hline \multirow[t]{2}{*}{ B2354 } & Indacaterol $75 \mathrm{mcg}$ & 163 & $0 \%$ & $0 \%$ & $0 \%$ & $0 \%$ \\
\hline & Placebo & 160 & & & & \\
\hline \multirow[t]{2}{*}{ B2355 } & Indacaterol $75 \mathrm{mcg}$ & 159 & $0 \%$ & $0 \%$ & $0 \%$ & $0 \%$ \\
\hline & Placebo & 159 & & & & \\
\hline \multirow[t]{4}{*}{ INHANCE } & Indacaterol $150 \mathrm{mcg}$ & 420 & $0 \%$ & $0 \%$ & $0 \%$ & $0 \%$ \\
\hline & Indacaterol $300 \mathrm{mcg}$ & 418 & & & & \\
\hline & Tiotropium 18 mcg & 420 & & & & \\
\hline & Placebo & 425 & & & & \\
\hline \multirow[t]{2}{*}{ INLIGHT-I } & Indacaterol $150 \mathrm{mcg}$ & 211 & $0 \%$ & $0 \%$ & $0 \%$ & $0 \%$ \\
\hline & Placebo & 205 & & & & \\
\hline \multirow[t]{3}{*}{ INLIGHT-2 } & Indacaterol $150 \mathrm{mcg}$ & 333 & $0 \%$ & $0 \%$ & $0 \%$ & $0 \%$ \\
\hline & Salmeterol $50 \mathrm{mcg}$ & 334 & & & & \\
\hline & Placebo & 335 & & & & \\
\hline \multirow[t]{2}{*}{ INSIST } & Indacaterol $150 \mathrm{mcg}$ & 560 & $0 \%$ & $0 \%$ & $0 \%$ & $0 \%$ \\
\hline & Salmeterol $50 \mathrm{mcg}$ & 563 & & & & \\
\hline \multirow[t]{2}{*}{ INTENSITY } & Indacaterol $150 \mathrm{mcg}$ & 797 & $0 \%$ & $0 \%$ & $0 \%$ & $0 \%$ \\
\hline & Tiotropium 18 mcg & 801 & & & & \\
\hline INVOLVE & Indacaterol $300 \mathrm{mcg}$ & 437 & $0 \%$ & $0 \%$ & $0 \%$ & $0 \%$ \\
\hline & Indacaterol $600 \mathrm{mcg}$ & 428 & & & & \\
\hline & Formoterol $12 \mathrm{mcg}$ & 435 & & & & \\
\hline & Placebo & 432 & & & & \\
\hline
\end{tabular}


Table I (Continued)

\begin{tabular}{lllllll}
\hline $\begin{array}{l}\text { Study name } \\
\text { or code }\end{array}$ & Interventions & $\begin{array}{l}\text { Number } \\
\text { randomized }\end{array}$ & $\begin{array}{l}\text { Received } \\
\text { concomitant } \\
\text { LAMA }\end{array}$ & $\begin{array}{l}\text { Received } \\
\text { concomitant } \\
\text { xanthines }\end{array}$ & $\begin{array}{l}\text { Received } \\
\text { concomitant } \\
\text { SAMA }\end{array}$ & $\begin{array}{l}\text { GOLD } \\
\text { stage IV } \\
\text { at baseline }\end{array}$ \\
\hline INTRUST-I & $\begin{array}{l}\text { Indacaterol I50 mcg } \\
\text { Placebo }\end{array}$ & 570 & $100 \%$ & $0 \%$ & $0 \%$ & $0 \%$ \\
INTRUST-2 & $\begin{array}{l}\text { Indacaterol I50 mcg } \\
\text { Placebo }\end{array}$ & 572 & $100 \%$ & $0 \%$ & $0 \%$ & $0 \%$ \\
\end{tabular}

Notes: aCross-over trial; bunpublished data (on file).

Abbreviations: GOLD, Global Initiative for Chronic Obstructive Lung Disease; IV, intravenous; LAMA, long-acting muscarinic anticholinergic; NR, not reported; SAMA, short-acting muscarinic antagonist.

measure, was analyzed at week 12 . Use of rescue medication (eg, as-needed salbutamol) was captured and analyzed as change from baseline in average number of puffs per day, using the maximum observed time for available data. Finally, the proportion of patients experiencing at least one exacerbation, captured as a COPD worsening adverse event, was analyzed for trials with a treatment duration of 24 weeks or longer reporting data for this outcome.

Some data imputations were required for standard errors, to maximize inclusion of change-from-baseline data into the meta-analyses. These imputations, together with further details on endpoint definitions are provided, where appropriate, in the data tables in the Supplementary material.

\section{Statistical analyses}

For network meta-analyses of dichotomous outcomes, a mixed log-binomial model was fit to estimate relative risks and confidence intervals. For network meta-analyses of continuous outcomes, a mixed normal-response model was fit to estimate mean differences and confidence intervals. These models included fixed treatment effects, fixed study effects, and random effects for the interaction between treatment and study. The random effects were included to allow the treatment effects to vary from study to study. The models were fit adopting an estimation approach using PROC GLIMMIX in SAS version 9.2 (SAS Institute Inc., Cary, NC, USA) and the methodology outlined by Jones et al. ${ }^{20}$

In addition to network meta-analyses, direct metaanalyses were performed using standard techniques to assess heterogeneity within the network and to support the analysis that required use of the adjusted indirect comparison technique. $^{21-23}$

Heterogeneity was investigated in several ways. For heterogeneity in trial designs, the a priori desire is to include a homogeneous set of trials in the network. To this end, trials were included/excluded based on permitted respiratory comedication during the trials; patient subgroups of data were used where patient-level data were available; and two additional indacaterol studies identified after completion of the systematic review were included, ${ }^{24}$ which allowed comparison of indacaterol with olodaterol when given with concomitant bronchodilation. For heterogeneity in analyses/ results, the generalized chi-squared statistic divided by the remaining degrees of freedom (should produce values close to 1.0 for a well-fitting model) was calculated and heterogeneity tests for direct meta-analyses were performed where appropriate.

\section{Results}

\section{Literature search results}

A total of 142 titles were retrieved through database searches and a further 31 through other sources such as conference web sites. After removal of duplicates, 110 titles and abstracts were screened. After applying the screening inclusion and exclusion criteria to both the titles/abstracts and the full-text articles, 23 publications, which reported data from a total of ten indacaterol trials (B1302, ${ }^{25}$ B2201, ${ }^{26}$ Study B2354, ${ }^{27}$ Study B2355, ${ }^{28}$ INHANCE,${ }^{29}$ INLIGHT- $1,{ }^{30}$ INLIGHT- $2,{ }^{31}$ INSIST, ${ }^{32}$ INTENSITY, ${ }^{33}$ and INVOLVE ${ }^{34}$ ), were eligible for metaanalysis, outlined in the PRISMA diagram in Figure $1 .{ }^{35}$ From the Boehringer Ingelheim trial database search, eight olodaterol trials were identified that met the inclusion criteria (study numbers 1222.11[NCT00782210], ${ }^{15} 1222.12$ [NCT00782509], ${ }^{15}$ 1222.13 [NCT00793624], ${ }^{16} 1222.14$ [NCT00796653], ${ }^{16}$ 1222.24 [NCT00931385], ${ }^{17} 1222.25$ [NCT00932646], ${ }^{17}$ 1222.39 [NCT01040689], ${ }^{18}$ and 1222.40 [NCT01040728]). ${ }^{18}$

During the meta-analysis phase of the project, two further publications were identified and included in the evidence base. ${ }^{24,36}$ Cope et $\mathrm{al}^{36}$ presented a network meta-analysis of four indacaterol trials (INVOLVE, INHANCE, INLIGHT-1, and INLIGHT-2) already included in the evidence base. This paper was, however, an additional source of outcomes data. 
Table 2 Included trials/treatments/outcomes

\begin{tabular}{|c|c|c|c|c|c|c|}
\hline $\begin{array}{l}\text { Study name } \\
\text { and/or code }\end{array}$ & $\begin{array}{l}\text { Trough } \\
\text { FEV }\end{array}$ & TDI & $\begin{array}{l}\text { SGRQ } \\
\text { total } \\
\text { score }\end{array}$ & $\begin{array}{l}\text { Rescue } \\
\text { medication } \\
\text { use }\end{array}$ & $\begin{array}{l}\text { SGRQ } \\
\text { response }\end{array}$ & Exacerbations \\
\hline I222.II & $\checkmark$ & & & $\checkmark$ & & $\checkmark$ \\
\hline 1222.12 & $\checkmark$ & & & $\checkmark$ & & $\checkmark$ \\
\hline 1222.13 & $\checkmark$ & $\checkmark$ & $\checkmark$ & $\checkmark$ & $\checkmark$ & $\checkmark$ \\
\hline 1222.14 & $\checkmark$ & $\checkmark$ & $\checkmark$ & $\checkmark$ & $\checkmark$ & $\checkmark$ \\
\hline I222.24 & $\checkmark$ & & & & & \\
\hline 1222.25 & $\checkmark$ & & & & & \\
\hline 1222.39 & $\checkmark$ & & & & & \\
\hline 1222.40 & $\checkmark$ & & & & & \\
\hline \multicolumn{7}{|l|}{ BI302 } \\
\hline \multicolumn{7}{|l|}{ B220I } \\
\hline B2354 & $\checkmark$ & & $\checkmark$ & $\checkmark$ & $\checkmark$ & \\
\hline B2355 & $\checkmark$ & & $\checkmark$ & $\checkmark$ & $\checkmark$ & \\
\hline INHANCE & $\checkmark$ & $\checkmark$ & $\checkmark$ & $\checkmark$ & $\checkmark$ & $\checkmark$ \\
\hline INLIGHT-I & $\checkmark$ & & $\checkmark$ & $\checkmark$ & $\checkmark$ & \\
\hline INLIGHT-2 & $\checkmark$ & $\checkmark$ & $\checkmark$ & $\checkmark$ & $\checkmark$ & $\checkmark$ \\
\hline INSIST & $\checkmark$ & & & & & \\
\hline INTENSITY & $\checkmark$ & $\checkmark$ & $\checkmark$ & $\checkmark$ & $\checkmark$ & \\
\hline INVOLVE & $\checkmark$ & $\checkmark$ & $\checkmark$ & $\checkmark$ & $\checkmark$ & $\checkmark$ \\
\hline INTRUST-I & $\checkmark$ & & & & & \\
\hline INTRUST-2 & $\checkmark$ & & & & & \\
\hline
\end{tabular}

Abbreviations: FEV , forced expiratory volume in I second; SGRQ, St George's Respiratory Questionnaire; TDI, Transition Dyspnea Index.

Mahler et $\mathrm{al}^{24}$ presented results for two indacaterol trials (INTRUST-1 and INTRUST-2) that were not otherwise identified at the time of the literature searches.

\section{Trial characteristics, treatment network, and data availability}

Table 1 lists the 20 included studies (18 from the systematic review and 2 identified after the review) and provides details on the included treatments, sample sizes, concomitant bronchodilator use, and whether the trials permitted patients with very severe COPD (GOLD stage IV) ${ }^{37}$ Further trial/baseline characteristics are presented in the Supplementary material. The Supplementary material also presents data for each of the outcomes for analysis and the descriptions of how the data were captured from each trial.

Table 2 presents an overview of the treatments and outcomes included in each trial. The resulting treatment network for this evidence base is presented in the Supplementary material (Figure A1). The different doses of olodaterol and indacaterol were considered as unique entities in this network and in these meta-analyses. Figure 2 presents an abbreviated version of the complete network and highlights the trials contributing to the indirect comparisons of primary interest (ie, the comparison of olodaterol $5 \mathrm{mcg}$ with indacaterol $75 \mathrm{mcg}$ and with indacaterol $150 \mathrm{mcg}$ ).
An important difference among the studies included in the evidence base is whether concomitant use of noninvestigational COPD treatments was permitted in the trials by design. Specifically, the olodaterol trials allowed concomitant use of LAMAs (tiotropium), short-acting muscarinic antagonists (SAMAs) (ipratropium), inhaled corticosteroids, and xanthines (theophylline). Four of the eight included olodaterol trials used stratified randomization according to LAMA use to ensure a balance in tiotropium users across treatment arms. Two olodaterol trials did not permit concomitant LAMA treatment, because tiotropium was one of the investigational drugs.

None of the indacaterol trials originally identified in the systematic literature review permitted any concomitant bronchodilator use (ie, SAMAs and LAMAs were not allowed) or xanthine use; all of the indacaterol trials permitted use of inhaled corticosteroids. In contrast, the two INTRUST trials required the co-administration of indacaterol with tiotropium; ${ }^{24}$ thus, $100 \%$ of patients in those trials received tiotropium in addition to indacaterol or placebo (inhaled steroids were also allowed, but not xanthines).

As-needed short-acting beta-agonists were permitted as rescue medication in all olodaterol and indacaterol trials, and their use was captured via the rescue medication outcome.

In addition, there were differences in the patient populations tested in the trials; while the olodaterol 


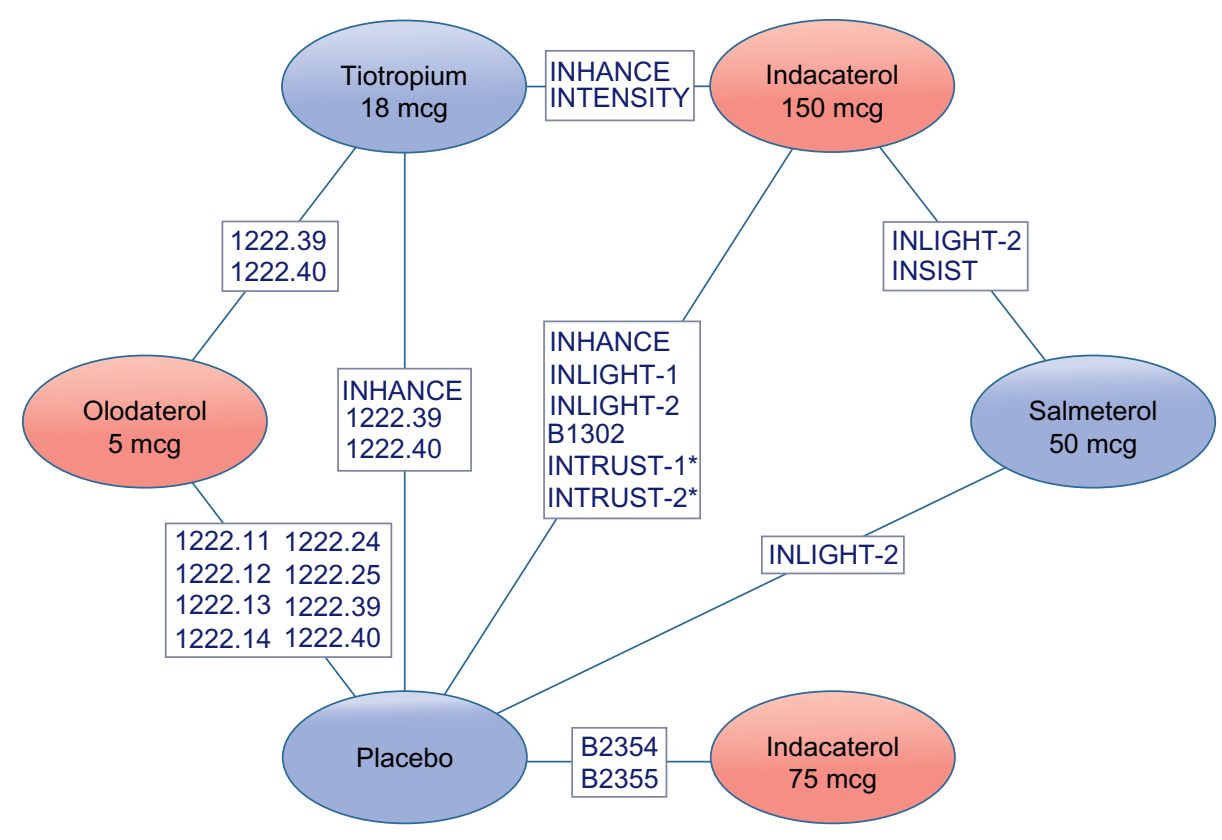

Figure 2 Network diagram for the primary treatment comparisons.

Note: *INTRUST-I and INTRUST-2 were identified after completion of the systematic review searches.

trials included patients with moderate to very severe COPD (GOLD II to GOLD IV), ${ }^{37}$ the indacaterol trials included only patients with moderate to severe COPD (ie, excluded patients with very severe COPD [GOLD stage IV]). ${ }^{37}$

\section{Meta-analysis strategy}

Given the findings from the trial characteristics summary (ie, to take into account heterogeneity in trial design, specifically concomitant bronchodilator use), two analyses were performed using subgroups of trials or patients that could be considered to be subject to similar trial conditions and therefore comparable. Given the data availability, these analyses could only be performed for the change from baseline in trough $\mathrm{FEV}_{1}$ at week 12.

The first analysis population was "LAMA-free" therapy and included all trials in which patients did not receive concomitant LAMA (ie, all indacaterol trials identified in the original systematic review and the olodaterol trials 1222.39 and 1222.40).

The second analysis population was "LAMA add-on therapy" and included all trials/subgroups in which all patients received concomitant or co-administered LAMA (ie, stratified subgroups of olodaterol trials 1222.11, 1222.12, 1222.13, and 1222.14; INTRUST trials for indacaterol). Because INTRUST had only placebo as a common comparator, direct meta-analysis and the adjusted indirect comparison technique were used for this analysis.

A third analysis population incorporated all trials ("full network") identified by the systematic review and was considered a sensitivity analysis for the trough $\mathrm{FEV}_{1}$ outcome. Given data availability, this population was the only possible analysis population for the other outcomes.

\section{Indirect comparison results}

Figure 3 presents the indirect treatment comparison results for the outcome "change from baseline in trough $\mathrm{FEV}_{1}$ " for each of the analysis populations. For the LAMA-free analysis, which included only trials explicitly excluding concomitant use of LAMA treatment, no differences were seen between olodaterol $5 \mathrm{mcg}$ and either indacaterol $75 \mathrm{mcg}$ or indacaterol $150 \mathrm{mcg}$. For the LAMA add-on analysis, which included only trials/subgroups receiving either concomitant or co-administered LAMA treatment, no differences were seen between olodaterol $5 \mathrm{mcg}$ and indacaterol $150 \mathrm{mcg}$. No data were available for indacaterol $75 \mathrm{mcg}$ for the LAMA add-on analysis. For the sensitivity analysis of the full network, the indirect comparisons favored indacaterol, statistically significantly for the $150 \mathrm{mcg}$ dose.

Figure 4 presents the indirect treatment comparison results for the continuous outcomes TDI, change from baseline in SGRQ total score, and change from baseline in rescue medication puffs per day for the full network analysis. Despite the known heterogeneity among the trials included in the full network, no differences were seen between olodaterol $5 \mathrm{mcg}$ and either indacaterol $75 \mathrm{mcg}$ or indacaterol $150 \mathrm{mcg}$.

Figure 5 presents the indirect treatment comparison results for the dichotomous outcomes SGRQ response and proportion of patients with exacerbations for the full network 


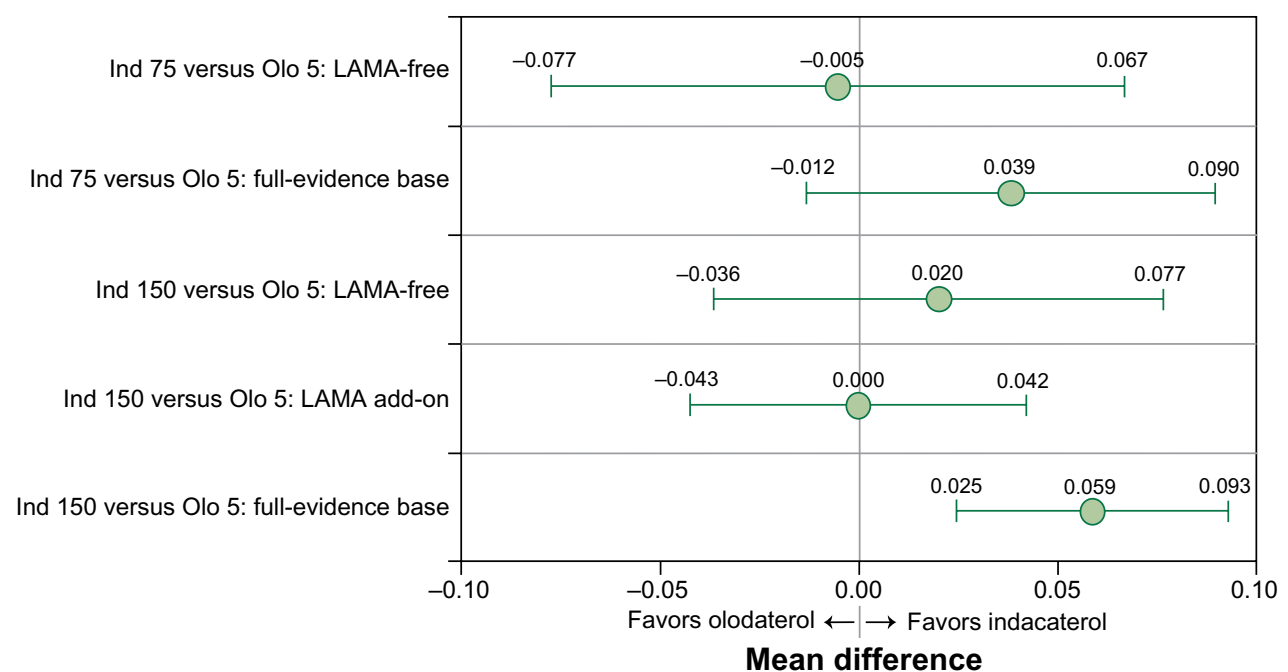

Figure 3 Forest plot for the trough FEV, analyses.

Notes: Values are mean difference and $95 \%$ confidence intervals for change in trough FEV from baseline (at week 6 or I2) for indacaterol 75 mcg (or I50 mcg) minus olodaterol $5 \mathrm{mcg}$. LAMA-free: trials excluding tiotropium; LAMA add-on: trials with concomitant tiotropium. Full evidence base: all trials within the network ("full network"). Abbreviations: $\mathrm{FEV}$, forced expiratory volume in I second; Ind 75, indacaterol 75 mcg; Ind I50, indacaterol I50 mcg; LAMA, long-acting muscarinic anticholinergic; Olo, olodaterol $5 \mathrm{mcg}$.

analysis. Again, despite the known heterogeneity among the trials, no differences were seen between olodaterol $5 \mathrm{mcg}$ and either indacaterol $75 \mathrm{mcg}$ or indacaterol $150 \mathrm{mcg}$, where data were available.

\section{Heterogeneity}

As shown in the separate analyses for change from baseline in trough $\mathrm{FEV}_{1}$, the identified heterogeneity in trial design with respect to concomitant bronchodilator use impacted the results and conclusions of the meta-analyses. Table 3 presents generalized chi-squared divided by the remaining degrees of freedom statistics for each network meta-analysis. Because the estimates were all fairly close to 1 , the models could be assumed to fit the data well, but this does not eradicate the issues of known trial heterogeneity. Table 4 presents direct meta-analyses heterogeneity test results for comparisons with placebo (where possible). These estimates do not display significant and consistent heterogeneity of trial results within each arm of the network diagram, but it should be noted that such heterogeneity tests can lack statistical power with

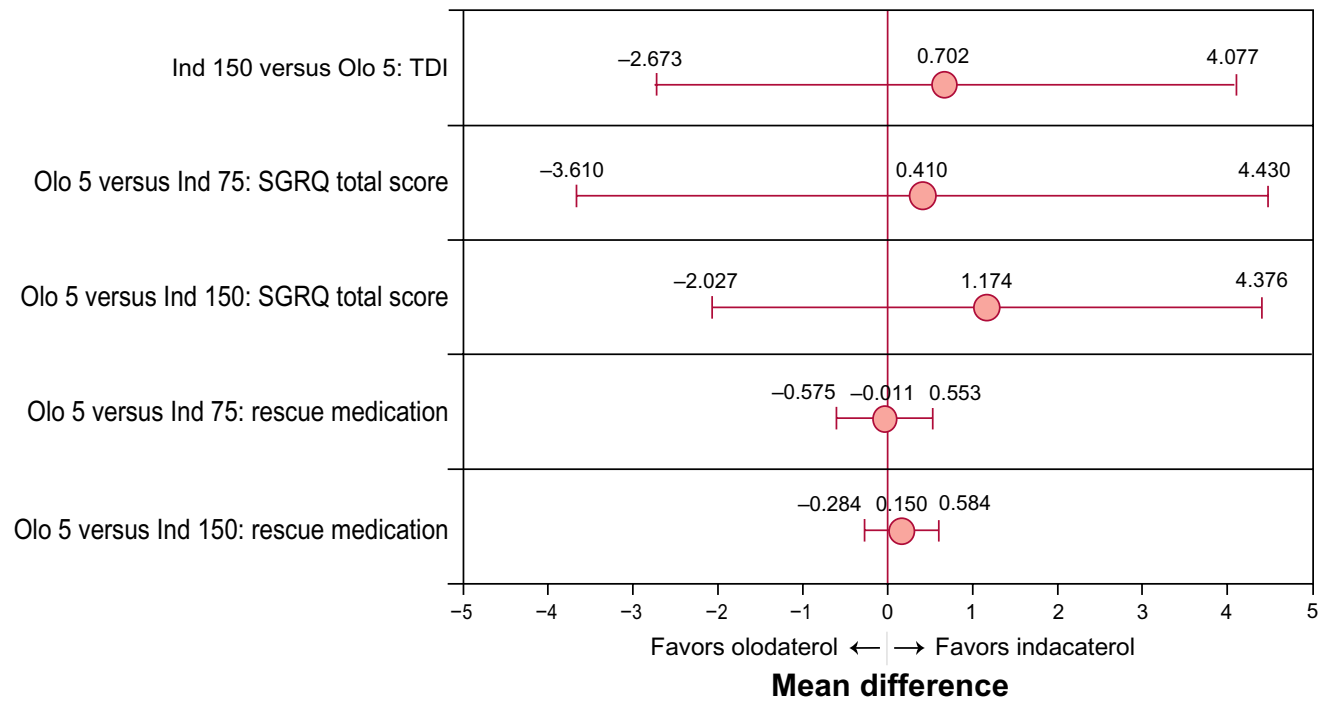

Figure 4 Forest plot for the TDI, SGRQ, and rescue medication analyses.

Notes: TDI: values are mean difference and $95 \%$ confidence interval for TDI focal score, change from baseline, for indacaterol I50 mcg minus olodaterol 5 mcg. SGRQ total score and rescue medication: values are mean difference and $95 \%$ confidence intervals for SGRQ total score and rescue medication use (puffs per day), change from baseline, for olodaterol $5 \mathrm{mcg}$ minus indacaterol $75 \mathrm{mcg}$ (or $150 \mathrm{mcg}$ ).

Abbreviations: Ind 75, indacaterol 75 mcg; Ind I50, indacaterol I 50 mcg; Olo, olodaterol 5 mcg; SGRQ, St George's Respiratory Questionnaire; TDI, Transition Dyspnea Index. 


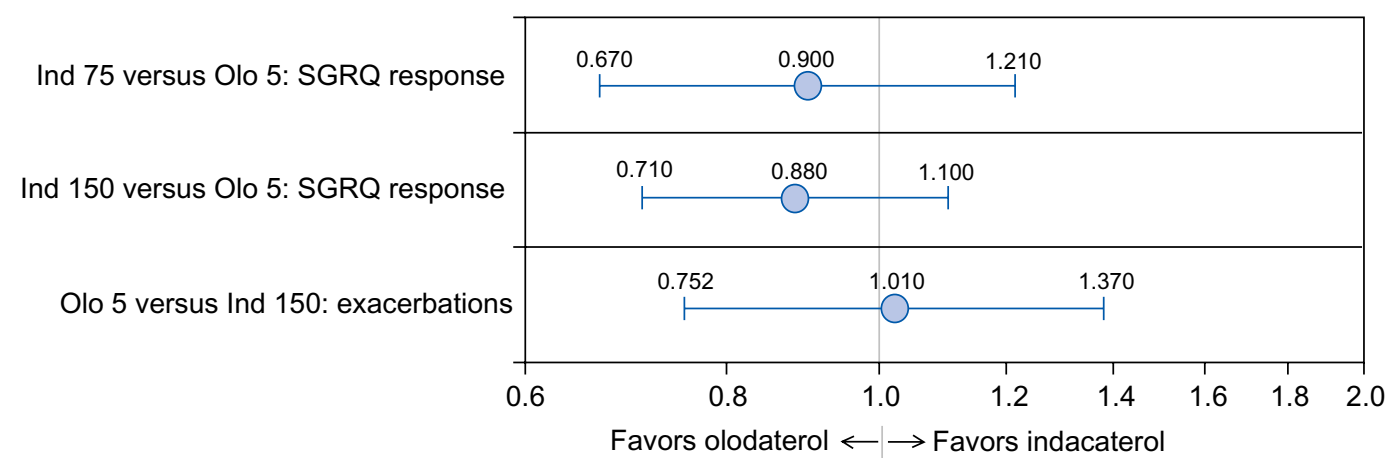

Relative risk

Figure 5 Forest plot for the SGRQ response and exacerbations analyses.

Notes: SGRQ response: values are relative risk and $95 \%$ confidence intervals for proportion of patients with an improvement in total SGRQ score of 4 points or more for indacaterol $75 \mathrm{mcg}$ (or $150 \mathrm{mcg}$ ) compared to olodaterol $5 \mathrm{mcg}$. Exacerbations: values are relative risk and $95 \%$ confidence interval for the proportion of patients with at least one exacerbation, for olodaterol $5 \mathrm{mcg}$ compared to indacaterol $150 \mathrm{mcg}$.

Abbreviations: Ind 75, indacaterol 75 mcg; Ind 150, indacaterol 150 mcg; Olo, olodaterol 5 mcg; SGRQ, St George's Respiratory Questionnaire.

small trial numbers. Additionally, information regarding the consistency assumption within the network as a whole is not provided due to the lack of head-to-head data between the selected treatments of interest. Forest plots for the direct meta-analyses are presented in the Supplementary material (Figure A2 through Figure A21).

\section{Discussion and conclusion}

In the absence of a direct head-to-head comparison, indirect comparisons can provide exploratory insights into the relative effectiveness of olodaterol and indacaterol. The current study indirectly compares olodaterol and indacaterol, while accounting for the considerable systematic heterogeneity in trial design among olodaterol and indacaterol trials. Evaluating lung function, trials/subgroups were selected in order to form indirect treatment comparisons based on patients subject to similar trial conditions, in which no evident differences between olodaterol and indacaterol were found.

Table 3 Network meta-analysis model fit

\begin{tabular}{ll}
\hline Endpoint & $\begin{array}{l}\text { Generalized chi-squared } \\
\text { statistic/degrees of } \\
\text { freedom }\end{array}$ \\
\hline${\text { Trough } F E V_{1} \text { : LAMA-free analysis }}_{\text {Trough } F E V_{1} \text { : full network analysis }}$ & 0.91 \\
SGRQ total score & 0.91 \\
TDI & 1.00 \\
Rescue medications & 0.64 \\
SGRQ response & 0.98 \\
Patients with $\geq$ I exacerbation & 1.03 \\
\hline
\end{tabular}

Note: Values close to 1.0 indicate a well-fitting model.

Abbreviations: $\mathrm{FEV}_{1}$, forced expiratory volume in I second; LAMA, longacting muscarinic anticholinergic; SGRQ, St George's Respiratory Questionnaire; TDI, Transition Dyspnea Index.
There were important differences among the olodaterol trials and indacaterol trials with respect to allowed concomitant COPD medications. Although all trials allowed concomitant inhaled steroid use and allowed the use of shortacting beta-agonists as rescue medication on an as-needed basis, the olodaterol trials also allowed concomitant use of LAMAs (tiotropium), SAMAs (ipratropium), and xanthines (theophylline), whereas the indacaterol trials did not.

Another notable difference was that olodaterol trials enrolled patients across the full disease severity spectrum, from moderate to very severe COPD (GOLD II-IV), ${ }^{37}$ whereas the indacaterol trials were restricted to patients with

Table 4 Direct meta-analysis heterogeneity test $P$-values

\begin{tabular}{|c|c|c|c|}
\hline \multirow[t]{2}{*}{ Outcome } & \multicolumn{3}{|c|}{$\begin{array}{l}\text { Heterogeneity test } P \text {-value (number of } \\
\text { included studies) }\end{array}$} \\
\hline & $\begin{array}{l}\text { Olodaterol } \\
5 \text { mcg versus } \\
\text { placebo }\end{array}$ & $\begin{array}{l}\text { Indacaterol } \\
75 \text { mcg versus } \\
\text { placebo }\end{array}$ & $\begin{array}{l}\text { Indacaterol } \\
\text { I } 50 \text { mcg versus } \\
\text { placebo }\end{array}$ \\
\hline $\begin{array}{l}\text { CFB trough FEV, } \\
\text { - LAMA-free }\end{array}$ & $0.98[2]$ & $0.55[2]$ & 0.31 [3] \\
\hline $\begin{array}{l}\text { CFB trough FEV, } \\
\text { - LAMA add-on }\end{array}$ & $0.37[4]$ & $\mathrm{n} / \mathrm{a}[0]$ & $0.54[2]$ \\
\hline $\begin{array}{l}\text { CFB trough FEV, } \\
\text { - full network }\end{array}$ & $0.09[8]$ & $0.55[2]$ & $0.31[3]$ \\
\hline $\begin{array}{l}\text { CFB SGRQ total } \\
\text { score }\end{array}$ & $0.68[2]$ & $0.93[2]$ & $0.02[3]$ \\
\hline TDI & $0.55[2]$ & $\mathrm{n} / \mathrm{a}[0]$ & $0.12[2]$ \\
\hline $\begin{array}{l}\text { CFB rescue } \\
\text { medication use }\end{array}$ & $0.19[4]$ & $0.18[2]$ & $0.87[3]$ \\
\hline SGRQ response & $0.26[2]$ & $0.94[2]$ & $0.03[3]$ \\
\hline $\begin{array}{l}\text { Patients with } \geq 1 \\
\text { exacerbation }\end{array}$ & $0.03[4]$ & n/a [0] & $0.48[2]$ \\
\hline
\end{tabular}

Abbreviations: $C F B$, change from baseline; $F E V_{1}$, forced expiratory volume in I second; LAMA, long-acting muscarinic anticholinergic; n/a, not available; SGRQ, St George's Respiratory Questionnaire; TDI, Transition Dyspnea Index. 
moderate to severe COPD (GOLD II/III). ${ }^{37}$ This difference in patient populations, and therefore potential lung function response, ${ }^{8}$ could not be addressed in this meta-analysis because olodaterol trials were not stratified for disease severity and therefore using the subgroup excluding GOLD IV patients for the meta-analysis would not be a randomized comparison.

The comparative efficacy of indacaterol and olodaterol differed depending on the subset of trials and patients included in the analyses. Change from baseline in trough $\mathrm{FEV}_{1}$ was similar among treatments when analyzing trials or data deemed to be comparable. In contrast, analyses not taking into consideration differences in allowed concomitant therapies can lead to inappropriate conclusions from the indirect comparisons. Thus, selecting studies of similar design for the drugs of interest is important in order to estimate the true differences in effect size.

Acknowledging the known differences of the patient populations recruited to the trials (very severe COPD patients included in trials of olodaterol, but not indacaterol), it is interesting to note that the absolute difference seen in the sensitivity analysis for trough $\mathrm{FEV}_{1}$ outcome is not replicated in either SGRQ endpoint evaluating health-related quality of life, where there are no differences among the treatments, or in the other endpoints investigated (exacerbations, rescue medication use, and TDI).

Assessing the results for external validity with previously published meta-analyses, ${ }^{36,38-41}$ the direct meta-analyses matched closely with the estimated treatment effects for indacaterol; however, because olodaterol data have only recently been published, the indirect comparisons have not been externally validated. The smaller effect sizes of LABA administered in addition to a LAMA, compared with the effect sizes of a LABA alone, were replicated. Specifically, for indacaterol $150 \mathrm{mcg}$ versus placebo, the effect size for trough $\mathrm{FEV}_{1}$ change from baseline was 0.07 liters when studied in combination with concomitant LAMA (Supplementary material, Figure A6), and 0.17 liters when studied in the absence of concomitant LAMA (Supplementary material, Figure A4). As with all meta-analyses, certain limitations should be considered when interpreting the results of this meta-analysis. Some between-trial differences in inclusion and exclusion criteria that influence the meta-analytic results were identified, especially with regard to the use of concomitant respiratory medication. The olodaterol trials could be considered to be studying treatment effects likely to be seen in real-world settings, whereas the indacaterol trials provide an estimate of absolute treatment effect. A limitation in the
LAMA-add on analysis of the lung-function endpoint is that only "add-on" tiotropium, and no other important bronchodilators (eg, SAMAs or xanthines), could be investigated, thus limiting the generalizability of the findings. Another limitation was that the "add-on" tiotropium in the olodaterol trials was concomitant medication, whereas in the indacaterol trials it was part of the investigational treatment. This limitation could lead to differences in application of, monitoring of, and compliance with the treatment.

A limitation with regard to the LAMA-free analysis for the lung-function endpoint was that the included olodaterol trials were cross-over trials lasting 6 weeks, whereas the indacaterol trials were parallel-group trials lasting 12 weeks. However, this trial heterogeneity may not influence the relative treatment effects and therefore indirect comparison results, because the relative treatment differences are maintained between week 6 and week 12, based on studies comparing olodaterol $5 \mathrm{mcg}$ and formoterol $12 \mathrm{mcg} .{ }^{10,15-18}$

Finally, analysis of endpoints other than change from baseline in trough $\mathrm{FEV}_{1}$ were possible only on the evidence base of trials that are inherently dissimilar with respect to concomitant bronchodilator use. Thus, these analyses should be interpreted with caution.

In conclusion, based on the analyses of change from baseline in trough $\mathrm{FEV}_{1}$, when compared under similar trial conditions, olodaterol $5 \mathrm{mcg}$ and indacaterol $75 \mathrm{mcg}$ or $150 \mathrm{mcg}$ seem to be equally effective in the treatment of patients with COPD. Other endpoints support this finding, although those analyses suffer from greater heterogeneity. Only head-to-head studies would be able to confirm the equal effectiveness of olodaterol and indacaterol. This research highlights the importance of concomitant COPD medication and study population when estimating treatment effects in COPD clinical trials.

\section{Disclosure}

This study was funded by Boehringer Ingelheim GmbH. RTI Health Solutions was a consultant to Boehringer Ingelheim $\mathrm{GmbH}$ for this study.

Mr Roskell is a full-time employee of Bresmed Health Solutions, but performed this work while employed by RTI Health Solutions.

Dr Anzueto participated in the writing of this manuscript and approved the final version. He has the following conflicts of interest: he is a member of the GOLD scientific committees and supports the implementation of the GOLD guidelines recommendations. He has also received honoraria, consulting fees, and advisory board 
and speaking fees from Bayer, Pfizer, GlaxoSmithKline, Boehringer Ingelheim, and Forest Laboratories. He is the principal investigator for research grants at the University of Texas Health Science Center at San Antonio and was paid for participating in multicenter clinical trials sponsored by GlaxoSmithKline and the National Institutes of Health.

Dr Hamilton, Dr Disse, and Dr Becker are full-time employees of Boehringer Ingelheim $\mathrm{GmbH}$. Boehringer Ingelheim has developed olodaterol.

\section{References}

1. Rabe KF, Hurd S, Anzueto A, et al. Global strategy for the diagnosis, management, and prevention of chronic obstructive pulmonary disease: GOLD executive summary. Am J Respir Crit Care Med. 2007;176(6): 532-555.

2. Global Strategy for the Diagnosis, Management and Prevention of COPD. Global Initiative for Chronic Obstructive Lung Disease (GOLD) 2013. Available from: http://www.goldcopd.org/. Accessed March 7, 2013.

3. Mroz RM, Minarowski L, Chyczewska E. Indacaterol add-on therapy improves lung function, exercise capacity and life quality of COPD patients. Adv Exp Med Biol. 2013;756:23-28.

4. Vogelmeier C, Kardos P, Harari S, Gans SJ, Stenglein S, Thirlwell J. Formoterol mono- and combination therapy with tiotropium in patients with COPD: a 6-month study. Respir Med. 2008;102(11):1511-1520.

5. Mills EJ, Thorlund K, Ioannidis JP. Calculating additive treatment effects from multiple randomized trials provides useful estimates of combination therapies. J Clin Epidemiol. 2012;65(12):1282-1288.

6. McKeage K. Indacaterol: a review of its use as maintenance therapy in patients with chronic obstructive pulmonary disease. Drugs. 2012;72(4):543-563.

7. Donohue JF, Jones PW. Changing patterns in long-acting bronchodilator trials in chronic obstructive pulmonary disease. Int J Chron Obstruct Pulmon Dis. 2011;6:35-45.

8. Albert P, Agusti A, Edwards L, et al. Bronchodilator responsiveness as a phenotypic characteristic of established chronic obstructive pulmonary disease. Thorax. 2012;67(8):701-708.

9. Decramer M, Celli B, Kesten S, Lystig T, Mehra S, Tashkin DP, UPLIFT investigaotrs. Effect of tiotropium on outcomes in patients with moderate chronic obstructive pulmonary disease (UPLIFT): a prespecified subgroup analysis of a randomized controlled trial. Lancet. 2009;374(9696):1171-1178.

10. Food and Drug Administration. Pulmonary-Allergy Drugs Advisory Committee Meeting: NDA 203108: Olodaterol (Proposed Trade Name Striverdi Respimat) for The Proposed Indication of Long-Term, OnceDaily Maintenance Bronchodilator Treatment of Airflow Obstruction in Patients with Chronic Obstructive Pulmonary Disease (Copd), Including Chronic Bronchitis and/or Emphysema; 2013. Available from: http:// www. assets.fiercemarkets.com/public/lifesciences/pulmonary.pdf. Accessed March 28, 2013.

11. Novartis Pharmaceuticals Canada Inc. Onbrez Breezhaler [product monograph]; 2011 [updated 2012]. Available from: http://www. novartis. ca/products/en/pharmaceuticals-o.shtml. Accessed March 27, 2013.

12. Novartis Pharmaceuticals Corporation. Arcapta Neohaler [prescribing information]; 2012. Available from: http://www.pharma.us.novartis. com/cs/www.pharma.us.novartis.com/product/pi/pdf/arcapta.pdf. Accessed March 27, 2013.

13. Novartis Europharm Limited. [Summary of product characteristics for Onbrez Breezhaler]; 2012. Available from: http://www.ema.europa. eu/ema/index.jsp?curl=pages/medicines/human/medicines/001114/ human_med_001219.jsp\&mid=WC0b01ac058001d124. Accessed March 7, 2013.
14. National Institute for Health and Care Excellence. Specification for Manufacturer/Sponsor Submission Of Evidence; 2009. Available from: http://www.nice.org.uk/aboutnice/howwework/devnicetech/Specific ationForManufacturerSponsorSubmissionOfEvidence.jsp. Accessed July 16, 2012.

15. Ferguson GT, Feldman GJ, Hofbauer P, et al. Efficacy and safety of olodaterol once daily delivered via Respimat ${ }^{\circledR}$ in patients with GOLD 2-4 COPD: results from two replicate 48-week studies. Int J Chron Obstruct Pulmon Dis. 2014:9:629-645.

16. Koch A, Pizzichini E, Hamilton A, et al. Lung function efficacy and symptomatic benefit of olodaterol once daily delivered via Respimat ${ }^{\mathbb{B}}$ versus placebo and formoterol twice daily in patients with GOLD 2-4 COPD: results from two replicate 48-week studies. Int J Chron Obstruct Pulmon Dis. 2014;9:697-714.

17. Feldman GJ, Bernstein JA, Hamilton A, Nivens MC, Korducki L, LaForce C. The 24-h FEV1 Time Profile of Olodaterol Once Daily via Respimat ${ }^{\circledR}$ and Formoterol Twice Daily via Aerolizer ${ }^{\circledR}$ in Patients with GOLD 2-4 COPD: Results from Two 6-week Crossover Studies. Springer Plus. In press 2014.

18. Lange P, Aumann JL, Hamilton A, Tetzlaff K, Ting N, Derom E. The 24-hour lung function time profile of olodaterol once daily versus placebo and tiotropium in patients with moderate to very severe chronic obstructive pulmonary disease. J Pulm Respir Med. In press 2014.

19. Centre for Reviews and Dissemination. CRD's Guidance for Undertaking Reviews in Health Care. University of York: Centre for Reviews and Dissemination; 2009. Available from: http://www.york.ac.uk/inst/crd/ pdf/Systematic_Reviews.pdf. Accessed August 30, 2012.

20. Jones B, Roger J, Lane PW, et al. Statistical approaches for conducting network meta-analysis in drug development. Pharm Stat. 2011;10(6):523-531.

21. Whitehead A. Meta-Analysis of Controlled Clinical Trials. Chichester, West Sussex, England: John Wiley and Sons Ltd; 2002.

22. Bucher HC, Guyatt GH, Griffith LE, Walter SD. The results of direct and indirect treatment comparisons in meta-analysis of randomized controlled trials. J Clin Epidemiol. 1997;50(6):683-691.

23. Song F, Altman DG, Glenny AM, Deeks JJ. Validity of indirect comparison for estimating efficacy of competing interventions: empirical evidence from published meta-analyses. BMJ. 2003;326:472.

24. Mahler DA, D’Urzo A, Bateman ED, et al. Concurrent use of indacaterol plus tiotropium in patients with COPD provides superior bronchodilation compared with tiotropium alone: a randomized, double-blind comparison. Thorax. 2012;67(9):781-788.

25. Kinoshita M, Lee S-H, Hang L-W, et al. Efficacy and safety of indacaterol 150 and $300 \mathrm{~g}$ in Asian COPD patients: a 12-week, placebo controlled study. American Thoracic Society International Conference; May 13-18, 2011; Denver, Colorado. Abstract no A1593.

26. Beier J, Chanez P, Martinot JB, et al. Safety, tolerability and efficacy of indacaterol, a novel once-daily beta(2)-agonist, in patients with COPD: a 28-day randomized, placebo controlled clinical trial. Pulm Pharmacol Ther. 2007;20(6):740-749.

27. Study B2354. Reported in Center for Drug Evaluation and Research summary review document for indacaterol; 2011. Available from: http://www.accessdata.fda.gov/drugsatfda_docs/ nda/2011/022383Orig1s000TOC.cfm. Accessed January 4, 2012.

28. Study B2355. Reported in Center for Drug Evaluation and Research summary review document for indacaterol; 2011. Available from: http://www. accessdata.fda.gov/drugsatfda_docs/nda/2011/022383Orig1s000TOC. cfm. Accessed January 4, 2012.

29. Donohue JF, Fogarty C, Lotvall J, et al. Once-daily bronchodilators for chronic obstructive pulmonary disease: indacaterol versus tiotropium. Am J Respir Crit Care Med. 2010;182(2):155-162.

30. Feldman G, Siler T, Prasad N, et al; INLIGHT 1 study group. Efficacy and safety of indacaterol 150 microg. once-daily in COPD: a doubleblind, randomized, 12-week study. BMC Pulm Med. 2010;10:11.

31. Kornmann O, Dahl R, Centanni S, et al. Once-daily indacaterol versus twice-daily salmeterol for COPD: a placebo-controlled comparison. Eur Respir J. 2011;37(2):273-279. 
32. Korn S, Kerwin E, Atis S, Amos C, Owen R, Lassen C. Indacaterol once-daily provides superior efficacy to salmeterol twice-daily in COPD: a 12-week study. Respir Med. 2011;105(5):719-726.

33. Buhl R, Dunn LJ, Disdier C, et al. INTENSITY study investigators. Blinded 12-week comparison of once-daily indacaterol and tiotropium in COPD. Eur Respir J. 2011;38(4):797-803.

34. Dahl R, Chung KF, Buhl R, et al. Efficacy of a new once-daily longacting inhaled beta2-agonist indacaterol versus twice-daily formoterol in COPD. Thorax. 2010;65(6):473-479.

35. Moher D, Liberati A, Tetzlaff J, Altman DG, The PRISMA Group. Preferred reporting items for systematic reviews and meta-analyses: The PRISMA statement. PLoS Med. 2009;6(6):e1000097.

36. Cope S, Capkun-Niggli G, Gale R, et al. Efficacy of once-daily indacaterol relative to alternative bronchodilators in COPD: a patient-level mixed treatment comparison. Value Health. 2012;15(3):524-533.

37. Global Initiative for Chronic Obstructive Lung Disease. Global Strategy for the Diagnosis, Management and Prevention of COPD, Revised 2011. Available from: http://www.goldcopd.org/uploads/users/files/ GOLD_Report_2011_Feb21.pdf. Accessed March 28, 2013.
38. Renard D, Looby M, Kramer B, Lawrence D, Morris D, Stanski DR. Characterization of the bronchodilatory dose response to indacaterol in patients with chronic obstructive pulmonary disease using model based approaches. Respir Res. 2011;12:54.

39. Bleecker ER, Siler T, Owen R, Kramer B. Bronchodilator efficacy and safety of indacaterol $150 \mu \mathrm{g}$ once daily in patients with COPD: an analysis of pooled data. Int J Chron Obstruct Pulmon Dis. 2011;6: 431-438.

40. Cope S, Capkun-Niggli G, Gale R, Jardim J, Jansen JP. Comparative efficacy of indacaterol $150 \mu \mathrm{g}$ and $300 \mu \mathrm{g}$ versus fixed-dose combinations of formoterol + budesonide or salmeterol + fluticasone for the treatment of chronic obstructive pulmonary disease - a network meta-analysis. Int J Chron Obstruct Pulmon Dis. 2011;6:329-344.

41. Cope S, Zhang J, Williams J, Jansen JP. Efficacy of once-daily indacaterol $75 \mu \mathrm{g}$ relative to alternative bronchodilators in COPD: A study level and a patient level network meta-analysis. BMC Pulm Med. 2012;12:29.

\section{Publish your work in this journal}

The International Journal of COPD is an international, peer-reviewed journal of therapeutics and pharmacology focusing on concise rapid reporting of clinical studies and reviews in COPD. Special focus is given to the pathophysiological processes underlying the disease, intervention programs, patient focused education, and self management protocols.

\section{Dovepress}

This journal is indexed on PubMed Central, MedLine and CAS. The manuscript management system is completely online and includes a very quick and fair peer-review system, which is all easy to use. Visit http://www.dovepress.com/testimonials.php to read real quotes from published authors. 